\title{
Comparison of Temperature Variations during Laparoscopic and Open Anterior Resections and Abdomino-perineal Resections
}

\author{
K. B. Galketiya ${ }^{1}$, V. Pinto $^{2}$, R. Anurada ${ }^{3}$, T. M. K. Jayasinghearachchi ${ }^{4}$
}

\begin{abstract}
Objective: To compare the incidence of hypothermia during open and laparoscopic colorectal surgeries.

Material and methods: A retrospective analysis of temperature variations of laparoscopic anterior resection and abdomino-perineal resections performed from January 2014 to April 2016 in the Professorial surgical unit at Teaching Hospital Peradeniya, Sri Lanka was evaluated. This was compared with that of open resections. Results: Thirty four patients were operated, twenty four patients being performed laparoscopically. The main temperature drop occurred soon after induction of anaesthesia, measured 15minutes after induction. The mean drop in laparoscopic group is 1.39 and 1.6 in open group. The drop in open group is higher which was statistically significant with a $\mathrm{p}$ value of 0.001 . The fluctuations each hour subsequently were less and temperature gains were noted in some hours in both groups which. The total drop at end of procedure was 1.04 in laparoscopy group and 2.19 in open group. The difference was statistically significant with a $\mathrm{p}$ value of 0.05 .
\end{abstract}

Conclusions: The temperature drop in open surgery group is higher than laparoscopic surgery group performed for carcinoma of rectum.

Key words: Hypothermia, Anterior resection, Abdomino-perineal resection

\section{INTRODUCTION}

Hypothermia is a complication of prolonged surgery $(1,2,3,4,5,6,16)$.

General anaesthesia, gas insufflation during minimal access surgeries, use of irrigation fluids, exposure of body cavities during open surgery and prolonged operating times contribute to hypothermia $(2,4,5)$. Hypothermia leads to an increase in systemic vascular resistance due to vasoconstriction and possible altered organ perfusion and a shift in the oxyhemoglobin dissociation curve to the left. These can cause tissue hypoxaemia. Cardiac

\footnotetext{
1. Department of Surgery, University of Peradeniya, Sri Lanka.

2. Department of Anaesthesiology, University of Peradeniya, Sri Lanka.

3. Department of Surgery, Teaching Hospital Peradeniya, Sri Lanka.

4. Department of Surgery, Teaching Hospital Peradeniya, Sri Lanka.
} 
arrhythmias, coagulation abnormalities, altered drug metabolism, and increased metabolic demands during re warming are reported due to hypothermia. A higher incidence of post-operative wound infection is also documented (8). Animal experiments have shown evidence for enhanced tumour growth attributed to hypothermia during laparoscopic procedures (7).

Warming of patient, use of warmed irrigation fluids and warmed intravenous infusions have shown to reduce the incidence of per operative hypothermia (1, $2,5)$.

Anterior resection (AR) and abdominoperineal resection (APR), which are the surgical treatment for carcinoma of rectum, may cause hypothermia by being prolonged procedures.

The current trend is to perform both procedures laparoscopically due to associated lower morbidity compared to open surgery $(9,10,11,12,13,14)$. The incidence of hypothermia has been demonstrated to be same during open and laparoscopic colorectal surgeries, in published data $(14,15,16)$.

\section{OBJECTIVE}

To compare temperature variations of open vs laproscopic AR and APR performed in our unit.

\section{PATIENTS AND METHOD}

A retrospective analysis of temperature variations of laparoscopic anterior resection and abdomino-perineal resections performed from January 2014 to April 2016 was evaluated. This was compared with that of open resections.

The following parameters were recorded.

1. Duration of surgery

2. Body temperature.

3. Gas insufflation volume

4. IV fluids

Warming devices were used and IV fluids were warmed. $\mathrm{CO} 2$ used to create pneumoperitoneum and, irrigation fluids were not warmed. The temperature was recorded by naso-pharyngeal probe.

\section{RESULTS}

Thirty four patients were operated. Twenty four patients underwent laparoscopic procedure. There were twenty anterior resections and four abdomino-perineal resections in the laparoscopy group.

Ten patients underwent open surgery which included six anterior resections and four abdomino-perineal resections.

The mean oral temperature recorded in ward was $370 \mathrm{C}$.

The mean volume of intravenous fluid infusion ranged from $150 \mathrm{ml} /$ hour for laparoscopy and $250 \mathrm{ml} /$ hour for open surgery. Volume of gas insufflated ranged 
from 50-100 litres per hour for laparoscopy. None required blood transfusions. The mean volume of irrigation fluid used in laparoscopy was
$30 \mathrm{ml} /$ hour. The average operating time of AR was 210min and for APR 180min.

Table 1. Mean temperature drop

\begin{tabular}{llll}
$\begin{array}{l}\text { Time from start of } \\
\text { procedure }\end{array}$ & $\begin{array}{l}\text { Mean change of temperature (Celsius) from previous value } \\
\text { Laparoscopic }\end{array}$ & Open \\
\hline $\mathbf{1 5}$ min after & Minus 1.39 & Minus 1.6 & Minus 1.6 \\
induction of GA & & & Minus 0.5 \\
$\mathbf{1}$ hour & Plus 0.29 & Minus 0.5 & 0 \\
$\mathbf{2}$ hours & Plus 0.1 & 0 & Plus 0.03 \\
$\mathbf{3}$ hours & Plus 0.02 & Plus 0.03 & Minus 0.1 \\
$\mathbf{4}$ hours & Minus 0.05 & Minus 0.1 & Minus 2.19 \\
Total drop at end & Minus 1.04 & Minus 2.19 & \\
\hline
\end{tabular}

\section{DISCUSSION}

Hypothermia is a known complication of major abdominal operations. $(1,2,3,4,5,6,16)$. There are reports showing no difference of the incidence of hypothermia in open and laparoscopy $(14,15,16)$.

In our series the main temperature drop occurs soon after induction of anaesthesia, measured 15minutes after induction. Temperature drop after induction of anaesthesia is a known phenomenon and is due to many factors such as vasodilatation and effects on the thermoregulatory centre.
The mean drop in laparoscopic group is 1.39 and 1.6 in open group. The drop in open group is higher which was statistically significant with a $\mathrm{p}$ value of 0.001.The fluctuations each hour subsequently was less and temperature gains were noted in some hours in both groups which is expected with thermoregulatory mechanisms being operational. The total drop at end of procedure was 1.04 in laparoscopy group and 2.19 in open group. The difference was statistically significant with a $p$ value of 0 . The higher drop in the open group 
may be explained by exposure of body cavity and intestines to exterior with greater heat loss.

However in both groups none of the patients dropped their temperature below 34.5 , the defined level of hypothermia.

Using warming of patient, use of warmed irrigation fluids and warmed intravenous infusions have shown to reduce the incidence of per operative hypothermia $(1,2,5,7)$. We used patient warming and warmed intravenous infusions during this study. In laparoscopy using warmed irrigation may have helped to further minimize temperature drop.

\section{CONCLUSIONS}

The temperature drop in open surgery group is higher than laparoscopic surgery group performed for carcinoma of rectum in this study. Use of warming devices and use of warmed intravenous fluids helps to minimize temperature drop.

\section{REFERENCE}

1. Bush HL, Hydo LJ, Fischer E, Fantini GA, Silane MF, Barie PS. Hypothermia during elective abdominal aortic aneurysm repair: The high price of avoidable morbidity Journal of Vascular Surgery 1995;21; 392-402.

2. Leben J, Tryba M. Prevention of Hypothermia during Surgery Contribution of Convective Heating System and Warm Infusion Annals of the New York Academy of Sciences Thermoregulation: Tenth International Symposium on the
Pharmacology of Thermoregulation pages 1997;813; 807-811

3. Kurz A, Daniel I, Sessler, Narzt E, Bekar A, Lenhardt R , Huemer G, Lackner F Postoperative hemodynamic and thermoregulatory consequences of intraoperative core hypothermia Journal of Clinical Anesthesia 1995;7 359-366.

4. Nduke CC, Puttick M, Coated P, Yong L, Peck D, Darzi A. Intraperitoneal hypothermia during surgery enhances post operative tumor growth Surg Endos 2002:16;611-615.

5. Kurz A, Sessler DI, Lenhardt R. Perioperative normothermia to reduce the incidence of surgical wound infection and shorten hospitalization The New England Journal of Medicine1996;334:1209-1215.

6. Redwine DB, Sharpe DR. Laparoscopic segmental resection of the sigmoid colon for endometriosis. J laparoendoscopic Surg 1991; 1:217-20.

7. Monson JR, Hill AD, Darzi A. Laparoscopic colonic surgery British Journal of Surgery 1995;82:150-7.

8. Decanini C, Milson JW, Bohm B, Fazio VW. Laparoscopic oncologic abdominoperineal resection. Dis Colon Rectum 1994;37:552-8.

9. Ziprin P, Ridgway PF, Peck DH, Darzi AW. The theories and realities of port site metastases: a critical appraisal. J Am Coll Surg 2002; 195:395-498.

10. Stocchi L, Nelson H, Young-fadok TM et al. Safety and advantages of laparoscoic vs open colectomy in the elderly, matched control study. Dis Colon rectum 2000; 43:326-32.

11. Danelli G, Berti M, Perotti V. et. al, Temperature control and recovery of bowel function after laparoscopic or laparotomic colorectal surgery in patients receiving combined epidural / general anaesthesia and postoperative analgesia. Anaesth Analg 2002;95:467-71.

12. Stewart BT, Stitz RW, Tuch MM, Lumley JW. Hypothermia in open and laparoscopic colorectal surgery. Diseases of the colon and rectum 1999; 42:1292-95.

13. AJ, Moyes D, Maddern GJ, Hewett PJ. Core temperature changes during open and laparoscopic colorectal surgery Surgical Endoscopy 1999; 13:480-83. 
GALKETIYA, K. B., PINTO, V., ANURADA, R., JAYASINGHEARACHCI, T. M. K., Comparison of temperature variations during laparoscopic and open anterior resections and abdomino-perineal resections. Sri Lanka Anatomy Journal (SLAJ), 1(1): 20-24, 2017.

14. H L Bush, L J Hydo, E Fischer,GA Fantini, M F Silane, $P$ S. Barie,Hypothermia during elective abdominal aortic aneurysm repair: The high price of avoidable morbidity Journal of Vascular Surgery 1995;21; 392-402

\section{CORRESPONDENCE:}

Professor K.B. Galketiya, Department of Surgery, Faculty of Medicine, University of Peradeniya. Sri Lanka.

Email-kbgalketiya@yahoo.com

Received: July 2017

Accepted: August 2017 